\title{
Metagenomic survey and whole genome sequencing of antimicrobial resistant bacteria in the sewage of a Japanese hospital
}

Miwa Katagiri ( $\sim$ girioyoshikazu0513@gmail.com )

Toho University Ohashi Medical Center https://orcid.org/0000-0001-5894-4563

Makoto Kuroda

National Institute of Infectious Desase

Tsuyoshi Sekizuka

National Institute of Infectious Desase

Norihide Nakada

Kyoto University

Yukitaka Ito

Toho University Ohashi Medhical Center

Masanobu Otsuka

Toho University Ohashi Medhical Center

Manabu Watanabe

Toho University Ohashi Medical Center

Shinya Kusachi

Toho University Ohashi Medhical Center

\section{Research}

Keywords: hospital sewage, antimicrobial resistance, antimicrobial-resistant bacteria, antimicrobial resistance gene, metagenome analysis, whole genome sequencing

Posted Date: August 5th, 2020

DOI: https://doi.org/10.21203/rs.3.rs-51067/v1

License: (c) (i) This work is licensed under a Creative Commons Attribution 4.0 International License.

Read Full License 


\section{Abstract}

Background The dissemination of antimicrobial-resistant bacteria (ARB) and the transfer of antimicrobial resistance genes (ARGs) are a threat to public health. Antibiotics are indispensable therapeutic agents essential for the treatment of infectious diseases; however, inappropriate use of antibiotics leads to the emergence of ARB. It is established that hospitals are closely involved in the spread of antimicrobial resistance (AMR), which impedes antibiotic treatment and subsequently increases mortality. In addition, excrement of patients or healthy carriers of ARB are discharged from the hospital sewage through the wastewater treatment plant (WWTP) into the rivers, causing an AMR burden on the environment.

Method Metagenomic analysis was performed on the hospital sewage samples, followed by whole genome sequencing of the extended spectrum $\beta$-lactamase (ESBL)-producing organisms (EPOs). A comparative genome analysis was also performed between EPO isolates from sewage and clinical isolates.

Results Metagenomic analysis showed that the hospital sewage tanks had bacterial flora corresponding to the human gut. During the study period, the hospital was relocated to a newly constructed building with new sewage tanks; however, the presence of ARB/ARGs in the new hospital sewage tanks became markedly equivalent to that of the old hospital within one month. The ESBL bla $a_{\mathrm{CTX}-\mathrm{M}}$ and carbapenemase $b / a_{\text {IMP }}$ genes were not much detected in the original hospital sewage samples by metagenome analysis, but selection on CHROMagar ESBL increased the sensitivity to detect those $\beta$-lactamase genes. Comparative genome analysis between sewage and clinical EPO isolates revealed partial similarity; however, most EPO isolates exhibited a notable difference $(\geq 50)$ in single nucleotide variations based on core-genome phylogeny. This result suggests that only some of the sewage EPO isolates were originated from the clinical patient. Therapeutic agents in the hospital sewage were analyzed and the concentration of levofloxacin and clarithromycin was 0.0325 and $0.0135 \mu \mathrm{g} / \mathrm{mL}$, respectively.

Conclusions Whole genome analysis between sewage and clinical isolates suggested that healthy or asymptomatic carriers may be involved in the contamination of hospital sewage. Moreover, the hospital sewage tank may serve as a hotspot for the horizontal transfer of ARGs under the selective pressure of antimicrobial agents. Therefore, ARB monitoring in hospital sewage is expected to detect the presence of carriers prior to nosocomial ARB outbreaks. In addition, hospital wastewater should be treated suitably to bring ARB below detectable levels to reduce the environmental AMR burden.

\section{Introduction}

The rapid dissemination of antimicrobial-resistant bacteria (ARB) has become one of the major public health concerns in the world. In case novel antibiotics against ARB are not developed, the annual number of deaths due to bacterial infections by ARB is predicted to increase to 10 million by 2050 [1]. In addition to nosocomial ARB infections, other environmental sources of ARB should also be investigated. The Global Action Plan on Antimicrobial Resistance drafted by World Health Organization [2] states that there 
is a need to understand the impact of human activities on the environment, particularly the spread and transfer of antimicrobial resistance genes (ARG) and strains. The Nippon National Action Plan on Antimicrobial Resistance One Health Report 2018 in Japan addressed that $12.4-27.5 \%$ of tested invasive Escherichia coli isolates were resistant to 3rd generation cephalosporins and $0.1 \%$ were resistant to carbapenems. Additionally, 5.7 - 9.4\% of tested invasive Klebsiella pneumoniae isolates were resistant to 3rd generation cephalosporins and $0.3-0.5 \%$ were resistant to carbapenems [3]. The isolation rates of these resistant strains are lower in Japan compared to other countries, but are certainly increasing. Therefore, antimicrobial resistance (AMR) should be well monitored in the $\beta$-lactam-resistant Enterobacteriaceae family of bacteria.

In addition to clinically isolated ARB, comparable ARB/ARGs have been detected from various environments around the world, including the effluent from wastewater treatment plants (WWTP) [4, 5], lakes and rivers [6-8], and soil [9]. In particular, extended spectrum $\beta$-lactamase (ESBL)-producing $E$. coli or carbapenemase-producing organisms (CPOs) have been detected in rivers, lakes [10-12], and WWTP treated water [13-15] in several countries, posing a potential risk of infection, and Japan is no exception $[16,17]$. Moreover, hospital wastewater is the most ARB-contaminated source in WWTP $[5,13,18-22]$ and there is concern about the relationship between hospital wastewater and environmental pollution [23, 24]. In particular, hospital wastewater is contaminated by ARB and residual antibiotics present in the excrement of patients, visitors, and medical personnel, and is considered to be a hot spot for the growth and propagation of ARB [5].

In hospital wastewater, residual antimicrobial agents, limited nutrients, and the structure of the microbial community may generate selective pressure for the development of ARB [5,25-28]. Genetic transfer of resistant genes from ARB to susceptible bacteria under this selective pressure may lead to the emergence of new populations of ARB $[26,29,30]$. ARB has been detected in subjects exposed to recreational water areas [31, 32], drinking water [33], seafood[34-37], and vegetables grown in irrigation water [3, 38]. Although it is not yet clear whether the hospital wastewater-related ARB disseminate into the water bodies, ARBs are observed to exhibit deleterious effects on human health. In the clinical setting, resistance to carbapenems in Enterobacteriaceaerelated infections [39] is a serious concern, owing to limited treatment options [40,41] and high mortality rates [42]. The presence of CPOs in hospital sewage $[5,13,21,22]$, urban sewage [43], and coastal water environments [31, 44] has also increased.

Therefore, active surveillance and management are necessary to avoid undesirable dissemination of ARB from hospital sewage to WWTP. Similar to the general sewage system, hospital sewage is also discharged into a public WWTP and released into rivers after primary purification, activated sludge process, and occasional chlorine disinfection. In recent years, technically and economically viable management strategies for ARB, ARG, and residual antibiotics discharged from hospitals have been studied in some countries [45-51]; however, there is a lack of similar reports from Japan. The aim of this study is to illustrate the contamination of hospital sewage with ARB containing resistant genes of clinical origin, and the effect of hospital relocation on the state of ARB/ARGs in the hospital sewage using comprehensive metagenomic sequencing. In addition, we compared the whole genome sequence of 
extended spectrum $\beta$-lactamase (ESBL)-producing organisms (EPOs) from hospital sewage and clinical isolates.

\section{Materials And Methods}

\section{Hospital setting}

The study was conducted at the Ohashi Medical Center in Toho University, located at Jonan-area suburb of Tokyo, Japan. The Ohashi Medical Center $(35.652573,139.685833)$ was opened in 1973 with a single East building and expanded to Central, Administration, and West buildings to increase patient capacity. Eventually, the number of beds in this medical center was 430 (Fig. 1). The hospital included the following departments in the West building (BW); Cardiology, Respiratory, Internal medicine, and Neurology wards, Intensive Care Unit, examination (dialysis, MRI, endoscopy, and radiography) and operating rooms; Administration building (BA); outpatient clinics of Surgery and Pediatric departments, and administrative staff room; Central building (BC); laboratories, Cardiovascular surgery, Orthopedics, Gynecology, and emergency outpatient clinics and inpatient wards of Gastrointestinal medicine, Surgery and Orthopedics, and dining rooms; East building (BE); outpatient clinics of Internal medicine, Plastic surgery, Ophthalmology, Otorhinolaryngology, Dermatology, and Urology and inpatient wards of Cardiology, Neurosurgery, Ophthalmology, and private wards.

As part of a renovation plan, a new hospital building (BN) $(35.652578,139.683959)$ with 319 beds was constructed approximately $50 \mathrm{~m}$ away from the old hospital $(35.652573,139.685833)$ and was inaugurated on June 20,2018. Since May 2018, we introduced a policy of restricted hospitalization of seriously ill patients, and transferred outpatients to neighboring hospitals to reduce the number of patients at the time of relocation. We stopped emergency services from June 6 to June 20 and outpatients from June 16 to June 19, and transferred the hospitalized patients to the BN on June 16 . We started accepting outpatients and hospitalized patients on June 20. The BN attends to 1000 outpatients per day and has a staff count of 2000 employees.

In both the old and new hospitals, stool and urine were stored in the underground sewage tanks without mixing with other drainage and were pumped to the sewage system several times a day (Fig. 1). In the old hospital, each building had respective sewage tanks (STW, STA, STC, and STE as shown in Fig. 1); however, the new hospital had two connected storage tanks of $22.5 \mathrm{~m}^{3}$ collecting all the sewage (STN shown in Fig. 1). It was impossible to quantify daily inflow and outflow of sewage tanks as there is no system for regular measurement. The sewage discharged from the tanks was sent to the wastewater treatment plants (WWTP) and treated using filtering, and microbiological and biochemical mechanisms. After treatments, the effluent was discharged into the nearby river.

\section{Sampling}




\section{Collection of water samples}

In the period from May 8, 2018 to Jun 12, 2018, sewage water samples were collected from four separate sewage tanks of the old hospital (STW, STA, STC, and STE) once a week. In the period from Jun 6 to July 17, sewage samples were collected from the sewage tank of the new hospital (STN) once a week. At 9 a.m., $20 \mathrm{ml}$ of sewage sample was collected in sterile bottles from the manhole of the sewage tank and processed for analysis within $2 \mathrm{~h}$.

\section{DNA-seq analysis}

Metagenomic analysis for whole organisms in original hospital sewage: First, $5 \mathrm{ml}$ of sewage was centrifuged at 5,000 $\mathrm{xg}$ for $5 \mathrm{~min}$ and the resultant cell pellet was vortexed with a remaining $500 \mu \mathrm{l}$ of sewage water. Next, the cell suspension was mixed with $500 \mu \mathrm{l}$ phenol/chloroform/isoamylalcohol (PCl) in a microcentrifuge tube with $2 \mathrm{ml}$ of beads. Cell breaking was performed by GenoGrinder 2010 by shaking at 1,500 rpm for $5 \mathrm{~min}$. The PCl mixture was centrifuged at 8,000 rpm for $5 \mathrm{~min}$, followed by DNA purification using a Gel DNA Recovery Kit, Zymoclean-96 (ZYMO RESEARCH, Irvine, CA,USA). A metagenome DNA-seq library was prepared using the QIAseq FX DNA library prep kit (Qiagen: Venlo, Netherlands), followed by sequencing using NextSeq 500 (Illumina) with NextSeq 500 mid output kit v2.5 (300 cycle).

Metagenomic analysis for EPOs on CHROMagar-ESBL: Two microliter of sewage sample was diluted with $100 \mu$ phosphate buffered saline (PBS), plated on CHROMagar-ESBL (bioMérieux, Marcy-l'Etoile, France) for selection of EPOs, and incubated at $36^{\circ} \mathrm{C}$ overnight. Cultured colonies were harvested and mixed with $1000 \mu \mathrm{l}$ of PBS. Next, $100 \mu \mathrm{l}$ of the bacterial suspension from CHROMagar-ESBL was transferred to a $2 \mathrm{ml} Z R$ BashingBead ${ }^{\text {TM }}$ Lysis tube, and mixed with $500 \mu \mathrm{PCl}$ and $500 \mu \mathrm{l}$ elution buffer (10 mM Tris pH 8.0). The tube was shaken by GenoGrinder 2010 at 1,500 rpm for 5 min. A metagenome DNA-seq library was prepared using the QIAseq FX DNA library prep kit (Qiagen: Venlo, Netherlands), followed by sequencing using NextSeq 500 .

\section{EPO isolates in hospital sewage}

To selectively grow EPO isolates from sewage samples, $50 \mu \mathrm{l}$ of sewage from the glycerol stocks prepared on May 22 and July 17 were diluted with $1000 \mu \mathrm{l}$ PBS, followed by plating on CHROMagarESBL, and incubation at $37^{\circ} \mathrm{C}$ overnight. Subsequently, 80 colonies were selected as potential EPOs and streaked on fresh CHROMagar-ESBL plates cultured at $37^{\circ} \mathrm{C}$ overnight to obtain pure cultures. ESBL producing bacteria were cultured in tryptic soy broth, and the cell suspension was transferred to $2 \mathrm{ml} \mathrm{ZR}$ BashingBead $^{\mathrm{TM}}$ Lysis tubes, and mixed with $500 \mu \mathrm{PCl}$. The tube was shaken by GenoGrinder 2010 at 
1,500 rpm for $5 \mathrm{~min}$. The PCl extract was centrifuged at 8,000 rpm for $5 \mathrm{~min}$, followed by DNA purification using a Gel DNA Recovery Kit, Zymoclean-96 (ZYMO RESEARCH). A DNA-seq library was constructed by a QIAseq FX, followed by sequencing using NextSeq 500.

\section{EPO clinical isolates}

All 20 EPO clinical isolates obtained between May 8 and July 17, 2018 were subjected to whole-genome sequencing as described above, and comparative genomics. Among the 20 clinical isolates, 12 isolates were obtained from outpatients and 11 isolates were obtained from urological patients. The samples were from urine, sputum, and central venous catheter $(75 \%, 10 \%$, and $10 \%$, respectively). Some specimens were obtained from the same patient through subsequent diagnosis. The ethical committee in Toho University Ohashi Medical Center waived the need for written consent regarding the research into bacterial isolates (Investigation No. pH). The personal data related to the clinical information were anonymized, and our procedure does not require a written consent from patients suffering from bacterial infections. Antibiotic susceptibility of samples cultured in the microbiology laboratory within the same period were determined using breakpoints standardized by the Clinical and Laboratory Standards Institute (CLSI). Screening (broth microdilution method) and confirmatory tests (the disk diffusion method) on the EPOs were conducted according to CLSI recommendations. (CLSI Performance Standards for antimicrobial disk susceptibility tests; Approved standard-13th edition CLSI document M02. Wayne, PA: Clinical and Laboratory Standards Institute; 2018).

\section{Bioinformatics}

To characterize microbial flora in the sewage samples, the sequencing reads were analyzed by MePIC2 [52] and Krona [53] and MEGAN v6 software [54]. To characterize isolates of bacterial species and identify antimicrobial resistance genes, sequencing reads were analyzed by multi locus sequence typing (MLST) [55] and ResFinder [56], respectively.

\section{Principal Coordinate Analysis (PCoA)}

The sequenced reads were assigned to a taxonomic hierarchy using MEGAN v6 software based on a megaBLAST nucleic acid homology search.

\section{Core genome single nucleotide variation phylogenetic analysis}


To compare the genotype of $37 \mathrm{E}$. coli strains isolated from patients and hospital sewage, the lllumina short reads, excluding low quality and adapter sequences, were aligned using BWA-MEM [57] against the complete chromosome sequences of $E$. coliSTN0717-11, followed by extraction of single nucleotide variants (SNVs) using VarScan v2.3.4 [58]. The prophage and repeat regions were predicted by PHASTER [59] and MUMmer 3 [60], respectively, and the detected SNVs in these regions were excluded. Regions of recombination in the chromosome were predicted using Gubbins v. 2.3.4 [61], followed by masking SNVs in the recombination regions. A maximum likelihood phylogenetic tree was constructed from SNV sites in the core genome region using FastTree2. De novo assembly was performed using SKESA v.2.3.0 [62] with short reads of each strain, followed by analyzing sequence type, putative serotype, and AMR gene prediction using pubMLST (https://pubmlst.org/escherichia/), SeroTypeFinder [63], and Bacterial Antimicrobial Resistance Reference Gene Database (BioProject ID: PRJNA313047), respectively.

\section{Measurement of concentrations of chemical compounds}

Forty drug components in the sewage samples were analyzed using solid-phase extraction (SPE) and ultra-performance liquid chromatography - tandem mass spectrometry (LC-MS/MS) based on a previously described method [64] with minor modifications. Briefly, the sample was filtered by a polyethersulfone membrane $(0.22 \mu \mathrm{m}$ pore size, Merck) and $100 \mathrm{ml}$ of the filtrate was spiked with $1 \mathrm{~g} / \mathrm{l}$ ascorbic acid, $1 \mathrm{~g} / \mathrm{I} \mathrm{EDTA}$, and a surrogate standard mixture, and then concentrated by SPE cartridge (Oasis HLB cartridges, $200 \mathrm{mg} / 6 \mathrm{cc}$, Waters, Japan). The analytes concentrated on the cartridge were extracted with $6 \mathrm{ml}$ of methanol before being measured by LC-MS/MS and quantified by the alternative surrogate method [64].

\section{Results And Discussion}

\section{Hospital setting}

The Ohashi Medical Center in Toho University is a general hospital opened in 1973. Prior to relocation, the hospital consisted of four buildings: West building (BW), Administration building (BA), Central building (BC), and East building (BE) and had a total of 430 beds, and accepted an average of 850 outpatients per day (Fig. 1). In the BW, there were intensive care wards (ICU, cardiovascular surgery, cardiovascular internal medicine, respiratory, and internal medicine), but no outpatient departments. In the BA, there were several outpatient departments, but the toilets were for only healthcare workers. In the BC, patients with digestive diseases, urinary diseases, and bone fracture were mainly accommodated, and the number of beds was the largest among the old hospital buildings. The BE included the highest number of outpatient departments with no intensive care wards.

The hospital relocated to the new building (BN) on June $20^{\text {th }}, 2018$. In the $B N$, all outpatient departments and wards were integrated into one building. The sewage from patients was not mixed with other 
wastewater sources (laboratory and general wastewater) in the wastewater systems of the old and new hospital (Fig. 1).

The average number of hospitalized patients in May was 246, and the number of hospitalized patients in $\mathrm{BC}, \mathrm{BE}$, and BW building started to decrease in June. Consequently, 66 patients were transferred to $\mathrm{BN}$ on June 16 (Fig. 2). After the new hospital was opened on June 20, we started outpatient examinations and accepted a new hospitalized patient, and the number of inpatients gradually increased and exceeded 250 on July 2.

\section{Metagenomic analysis of tank flora in each building}

To elucidate the differential microbial flora in the hospital sewage tank (tank flora), metagenome DNAseq analysis of sewage samples was conducted. The dominant bacteria in the sewage were classified according to the metagenomic data $\varangle$ Supplemental Data Set S1), wherein the most common genus was Aeromonas, followed by Citrobacter and Bacteroidetes (Fig. 3a). In addition, the proportion of genera varied depending on the building; the largest genus comprised of Citrobacter in STA, Aeromonas in STC, Bacteroides in STE, Acinetobacter and Citrobacter in STW, and variable genera in STN. Notably, less diversity was observed in STA (Fig. 3b) tanks because the toilet users in BA were limited to staff members, and the amount of excretion was also small.

In our hospital's sewage tank, bacteria originating from human gut flora were expected to be predominant as only stool and urine excreted from the toilet are stored. Composition of bacterial flora in hospital sewage has been reported to comprise of human gut flora Bacteroides, Faecalibacterium, Bifidobacterium, Blautia, Roseburia, and Ruminococcus, in addition to Klebsiella, Aeromonas, Enterobacter, Prevotella, and Comamonas [5]. In the gut flora of healthy Japanese adults, the anaerobes Bifidobacterium, Blautia, Bacteroides, Faecalibacterium, Eubacterium, Ruminococcus, and Collinsella are predominant [66]. However, hospital sewage is mainly influenced by the patients' gut flora, which is different from healthy individuals. Thus, flora in each tank at the old hospital (STA, STW, STC, and STE) exhibited different bacterial compositions depending on the characteristics of the patients present in each building (Fig. 1).

Since June 5th, only construction company and hospital staff visited the BN, and the STN was composed of a few genera such as Citrobacter, Aeromonas, Escherichia, and Klebsiella. Thereafter, Arcobacter, Citrobacter, Aeromonas, Bacteroides, and Acinetobacter comprised the main constituents, and the variety of genera increased with time. In the STN, the composition of bacteria was partially consistent with that in the STC, STE, and STW. It appears that all bacterial species detected in the old sewage tanks (STA, STC, STE and STW) were integrated into STN. For instance, Aeromonas originated from STC and Citrobacter and Acinetobacter originated from STW. In the STN, Comamonas and Arcobacterwere significantly detected after the transfer of inpatients. Comamonas is a genus of aerobic proteobacteria, generally considered as environmental bacteria with less pathogenicity. It is reported that one of the 
Comamonas species, C. testosterone, aerobically degrades testosterone when cultured in testosteronecontaining media [67]. In the STN, the enrichment of Comamonas in sewage suggests the possibility of its role in decontamination of medical compounds. Arcobacter spp. are gram-negative rod-shaped bacteria of the family Campylobacteraceae. A. butzleri, A. cryaerophilus, and A. skirrowii have been implicated in severe acute gastrointestinal infections and bacteremia after exposure to shellfish and/or ingestion of contaminated water, or inadequately cooked meat/shellfish [International Commission on Microbial Specification for Foods (ICMSF, 2002)]. In the present study, there were no instances of infectious enteritis due to Arcobacter in the hospital; however, the causative bacteria of infectious enteritis are not easily identifiable, except in limited conditions. Arcobacter is detected in WWTP in several countries [68-71], and the presence of antimicrobial resistant Arcobacterhas also been documented [70, 72]. E. coli and Klebsiella were not abundant, but were consistently detected, in all sewage tanks of buildings. It is unclear whether the difference in the bacterial composition of each tank reflects characteristics of each building (department, diseases, drugs administered). Unlike the sewage system in the old hospital (STA, STC, STE, and STW), the new hospital has a single sewage tank (STN). Thus, the bacterial composition of STN looks similar to that of STW, suggesting that the flora in STW was most influenced by STN.

Similarity and diversity of bacterial population amongst tanks was analyzed using principal co-ordinates analysis (PCOA) based on bacterial genus level (Fig. 4). A PCoA used a total of 25 sewage samples of each tank excluding STA, and showed that the STN and STW groups were closely plotted, while the STE and STC groups were largely separated. The BW and BN contain rooms where seriously ill patients are treated, such as intensive care unit (ICU), coronary care unit (CCU), and respiratory disease wards (Fig. 1). According to PCoA analysis, the distribution of flora in STN after the transfer of patients was similar to that of STW, indicated by the presence of Aeromonas, Citrobacter, and Comamonas (Fig. 4). The distribution of tank flora can be strongly influenced by the wards for patients who were prescribed strong doses of antibiotics and other therapeutic agents. Furthermore, tank flora can be instantly affected by excrement of hospital patient/staff/visitor because the bacterial composition of STN was comparable to that of STW within one month after the relocation.

In this study, the old hospital sewage tanks (STA, STC, STE, and STW) were separately installed in each building; thus, a marked difference was observed among tanks. In contrast, it was difficult to identify the relationship between the flora and specific departments in the new hospital sewage tank, STN, because of a single tank in the building. For the purpose of monitoring department-specific ARB, it may be beneficial to install department-specific sewage tanks.

\section{Analysis of $\beta$-lactamase genes in flora of tanks}

The metagenome next generation sequence (NGS) reads corresponding to $\beta$-lactamase genes were identified in original hospital sewage samples (Fig. 5a) and EPOs from each tank were selected on CHROMagar ESBL (Fig. 5b). In the original hospital sewage samples, various $\beta$-lactamase genes such as 
$b / a_{\mathrm{GES}}, b / a_{\mathrm{OXA}}$, and $b / a_{\mathrm{CMY}}$ were detected in flora of STC, STW, and STN, while almost no $\beta$-lactamase genes were detected in flora of STA and STE. This may be due to the limited sensitivity of metagenomic detection in this study. The b/a $a_{\text {MPP }}$ gene was detected from STC and STW samples, and the bla $a_{\text {CTX-M }}$ gene was detected from STW and STN samples (Fig. 5a). CHROMagar ESBL selection facilitated the detection of EPOs as $\beta$-lactamase genes were detected in STA and STE using this technique. Moreover, $b / a_{I M P}$ and $b / a_{\text {CTX-M }}$ genes were present in flora of all sewage tanks (Fig. 5b).

\section{Genome comparison between sewage and clinical isolates}

Although metagenomic analysis showed the number of each bacterial species and ARG, it is impossible to deduce which bacterial strain carries a particular ARG. Thus, whole genome sequencing was performed for 78 EPO isolates from STW0522 and STN0717, and 20 EPO clinical isolates (May 8, 2018 to July 17,2018 ) for comparison of genomic sequences of EPOs from sewage tanks and clinical sources. In the STW0522 sample, bacteria such as E. coli, Klebsiella, Enterobacter, Citrobacter, and Achromobacter were detected, and in the STN0717 sample, E. coli, Klebsiella, Enterobacter, and Citrobacterwere detected (Table 1). Clinical isolates included only E. coli and the Klebsiella spp., wherein E. coli displayed sequence variations compared to sewage isolates (Table 2).

A pairwise single nucleotide variation (SNV) analysis of the core genome was conducted for all $E$. coli strains (Fig. 6). The E. coli sequence types (STs) included ST393 $(n=16)$, ST38 $(n=8)$, ST131 $(n=5)$, ST1011 $(n=4)$, ST12 $(n=1)$, ST73 $(n=1)$, ST9586 $(n=1)$, and ST224 $(n=1)$. E. coliST12, ST73, ST131, and ST1011 were detected exclusively in clinical isolates (Table 2). Clinical EPO isolates (THO-008 and -019 from same patient; Patient-No. 8) comprised of ST393 harboring $b / a_{\mathrm{CTX}-\mathrm{M}-27}$ and there was no difference in SNVs between isolates (Fig. 6), indicating that the clone was identified from the same patient. In addition, these clinical isolates also showed no SNVs with sewage isolates (14 isolates; STN0717-1 to -11, 14, 15, and 19), suggesting that these sewage isolates may have originated from the same patient (Patient-No. 8) (Supplemental Data Set S2). Monitoring of ARB/ARGs in hospital sewage may enable detection of latent carriers or nosocomial infections.

Three ST38 clinical isolates (THO-002 identified from Patient-No. 2, THO-007 and -020 identified from Patient-No. 7) harboring $b / a_{\text {CTX-M-14 }}$ were identified within a three-week duration, and further SNV analysis revealed marked 21-110 SNVs in the core-genome. This result suggested that all three isolates are closely related; however, there was no strong evidence of a nosocomial outbreak associated with this single clone. It is reported that molecular evolution of $E$. coligenome is possible with less than $5 \mathrm{SNVs}$ within a 60-day duration [73]. In contrast, ST38 sewage isolates (STN0717-12, -13, -17, -18, and -21) harboring $b / a_{\mathrm{CTX}-\mathrm{M}-55}$ exhibited strict clonality with $3 \mathrm{SNVs}$, and showed $\geq 123 \mathrm{SNVs}$ with clinical isolates (THO-002, -007, and -020) (Fig. 6). ST131 is an E. coli isolate responsible for a worldwide pandemic and carries a broad range of pathogenicity and antimicrobial resistance-associated genes, including a variety of $\beta$ lactamase genes (CTX-M family, TEM, SHV, and CMY $\beta$-lactamases) on a transferable plasmid [74-77]. 


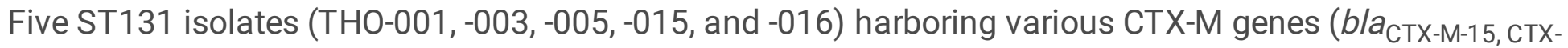
M-27, CTX-M-44) were identified from individual patients and 32-84 SNVs were observed between the isolates, suggesting that the isolates were closely related but not identical (Fig. 6).

Thus far, the healthy carriage rate of EPOs has been rising worldwide. In Japan, detection rate of EPO was reported at $12.2 \%$ in healthy adult volunteers [78] and at $15.6 \%$ in healthy food handlers [79]. Additionally, it is reported that $92.9 \%$ of EPOs were $b / a_{\text {CTX-M }}$ gene positive [80]. The CTX-M genes (b/a $a_{\text {CTX- }}$ $\mathrm{M}-14, b / a_{\mathrm{CTX}-\mathrm{M}-27}, b / a_{\mathrm{CTX}-\mathrm{M}-15}$ and $b / a_{\mathrm{CTX}-\mathrm{M}-2}$ in descending order in size) are mainly identified in Japan and its reported sequence is similar to that observed in EPOs in the hospital sewage and clinical isolates in this study (Table 3). Prominent global trends in CTX-M epidemiology indicate that the reduced occurrence of bla $a_{\mathrm{CTX}-\mathrm{M}-2}$ and emergence of $b / a_{\mathrm{CTX}-\mathrm{M}-27}$ [75], suggesting that healthy carriers could be at risk for nosocomial infections by EPOs.

In the sewage samples, isolates possessed various $\beta$-lactamase genes; bla ${ }_{\mathrm{SHV}-12}, b / a_{\mathrm{CTX}-\mathrm{M}-14}$, and $b / a_{\mathrm{CTX}}$ M-62, in Enterobacter kobei, bla $a_{\mathrm{SHV}-12}$ in Enterobacter cloacae, bla $a_{\mathrm{CTX}-\mathrm{M}-9}$ in Enterobacter homaechei, bla $a_{\mathrm{IMP}-}$ ${ }_{11}$ in Pseudomonas monteilii, and bla SHV-12 $_{2}$ in Raoultella planticola (Supplemental Data Set S2). Many of the potential EPOs harboring ARGs in the sewage tanks were different from the clinical isolates. It is not clear whether these EPOs were excreted by healthy carriers or were transformed by acquiring the ARGs in the sewage tank.

Among the 156 CHROMagar ESBL-positive strains from hospital sewage tanks (STW0522 and STN0717) (Supplemental Data Set S2), carbapenemase gene (b/a IMP-11) was identified only in Pseudomonas monteilli, but not in E. coli and Klebsiella (Table 3). The bla $a_{\mid \mathrm{MP}-11}$ gene was originally found in clinical isolates of E. cloacae [81], K. pneumoniae, E. coli [82], P. aeruginosa [83], and Acinetobacter species [84] in Japan. P. monteilli is a Gram-negative bacteria of the $P$. putida group and occurs in the soil, garbage, and drains [85]. P. monteilli is less pathogenic to humans, but was isolated from clinical samples [49, 86$88]$ and hospital environment $[85,89]$. P. monteilii may play a role as an Metallo- $\beta$-lactamase (MBL) reservoir and transfer of MBL genes to other species such as Enterobacteriaceae may be a cause of concern, especially in hospital sewage tanks $[49,87,89,90]$.

\section{Concentration of residual antimicrobial agents in hospital sewage tanks}

There is a possibility that sewage tanks provide an environment conducive to the development of novel drug resistant bacteria. Sewage tanks are reservoirs of ARGs and transfer of genes between bacteria may occur under the selective pressure of antimicrobial agents and antiseptics. Indeed, concentration of chemical contaminants in the tank (Table 4) showed that the most predominant antimicrobial agent was levofloxacin $(32,500 \mathrm{ng} / \mathrm{l})$ and clarithromycin $(13500 \mathrm{ng} / \mathrm{l})$, which may potentially exhibit inhibitory action in the sewage tank environment, although their concentrations were below MIC breakpoints. 
In hospital wastewater, ciprofloxacin concentration was reported to be $22,000-179,000 \mathrm{ng} / \mathrm{L}$ in Germany [91], 19,110 - 428,00 ng/L in Vietnam, and clarithromycin was reported to be up to $960 \mathrm{ng} / \mathrm{L}$ in Portugal [92] and $760-72,800 \mathrm{ng} / \mathrm{l}$ in Singapore [27]. The present study detected an antibiotic concentration similar to the above reports. Although $\beta$-lactam antibiotics were not measured in this study, they are known to be almost undetectable in environmental samples [93, 94]. This is because unstable lactam rings increase susceptibility of $\beta$-lactam antibiotics to hydrolysis immediately after excretion $[94,95]$. Hospital sewage tanks containing a large amount of residual antibiotics [96] may change the composition of tank flora and further promote the development of AMR by high selective pressure on bacteria $[20,97,98]$. Antibiotics exert selective pressure in favor of the growth resistant bacteria, even at very low concentrations [99-101]. Moreover, there are some reports that concentration of antibiotics in hospital sewage are often higher than the reported no-effect or minimum concentrations for resistance selection, suggesting that the selection of ARB can occur in this environment $[97,102]$. We presume that selective pressure of antibiotics exists in our hospital sewage tanks; however, this will be verified in future studies.

Horizontal gene transfer is a cause of great concern as it is one of the most important mechanisms of the spread of antibiotic resistance in the environment $[103,104]$. It is suggested that nutrient-rich environments such as wastewater offer optimal conditions for horizontal gene transfer, involving the transconjugation of AMR plasmids encoding ARGs [105] and transformation of non-pathogenic bacteria into reservoirs of ARGs. It is known that a microbial gut flora composed of a spectrum of bacteria functions as a reservoir for ARGs and horizontal plasmid transfer between bacteria is common [103]. This is plausible as sewage tanks consists of an accumulation of excrement and acquisition of resistance may occur frequently.

In Sweden, carbapenemase-producing Klebsiella was also detected from clinical specimens, in Svartån River and the rivers downstream of it [11]. In Japan, KPC-2 producing Klebsiella [16, 17] and NDM-5coproducing Escherichia coli [17] were detected from the effluent of urban wastewater treatment plants. Effective actions should be taken including advanced wastewater treatment processes such as ozone and UV treatment $[47,106,107]$, and ultrafiltration [108] to accelerate the removal of ARB in WWTP. However, even the above methods do not ensure a complete removal of resistant bacteria, therefore, treatment processes may be introduced prior to the release of hospital sewage into the main sewage to reduce ARB and residual drug concentrations. In Japan, there are a few reports of contamination of sewage with ARB and presence of ARGs in microbial flora of hospital sewage tanks $[109,110]$. Nevertheless, this study is the first comprehensive description of AMR in a hospital setting using metagenomic and whole genome analysis.

\section{Conclusions}

In many countries including Japan, hospital wastewater is discharged into sewage without treatment, and ARB are detected from the drained rivers, and soil and water environment. Therefore, the frequency of ARGs in bacteria increases and consequently, there is an AMR burden on the environment. The 
dissemination of ARB/ARGs in the environment can increase the risk of infectious diseases [18]; however, there are very few direct suggestive data about their epidemiological effects [111]. Our study reveals the presence of ARB/ARGs in the hospital sewage tank and suggests that every hospital patient/staff/visitor can be a potential carrier. Furthermore, the hospital sewage tank is a hot spot where various bacterial species may acquire ARGs. Monitoring of ARB/ARGs in hospital sewage is expected to identify the presence of carriers, and control nosocomial outbreaks and dissemination of ARB/ARGs in the community.

\section{Declarations}

\section{Ethics approval and consent to participate}

Not applicable

\section{Consent for publication}

Not applicable

\section{Availability of data and materials}

The metagenomic short-read sequences for DNA-seq were deposited in the DNA Data Bank of Japan (BioProject PRJDB9036; BioSample SAMD00195117-SAMD00195180; DRA accession DRA009310) (Supplemental Data Set S1). The NGS data for whole genome sequencing were deposited in the DNA Data Bank of Japan (BioProject PRJDB9036; BioSample SAMD00195843-SAMD00196018; DRA accession DRA009309). All complete sequences in this study are available from the DDBJ/ENA/GenBank database (accession numbers AP022380-AP022556), as shown in the supplementary data files (Supplemental Data Set S2).

\section{Competing interests}

The authors declare that they have no competing interests.

\section{Funding}

This work was supported by the Research Program on Emerging and Re-emerging Infectious Diseases of Japan Agency for Medical Research and

\section{Author Contributions}

MK2, MW, and SK designed the study. MK1 contributed to the sampling of waste water samples. MK2 conducted bacterial isolation and performed genome sequencing. TS performed the comparative genome analysis. NN conducted a measurement of concentration of chemical compounds. MK1 and MK2 wrote the manuscript.

\section{Acknowledgments}


The authors would like to thank Dr. Yoshinobu Sumiyama, Chairman, Toho University and Dr. Satoshi Iwabuchi, Hospital Director, Ohashi Medical Center, Toho University for giving us permission to conduct this research. We are grateful to Mr. Umezu Masahiro and other hospital equipment personnel for their support in sampling of hospital sewage. We gratefully acknowledge the staff members of the Laboratory of Bacterial Genomics, Pathogen Genomics Center, National Institute of Infectious Diseases in Tokyo Japan.

\section{References}

1. O'Neill J: Antimicrobial Resistance: Tackling a crisis for the health and wealth of nationsThe Review on Antimicrobial Resistance, Chaired by Jim O'Neill. 2014.

2. organization Wh: Global action plan on antimicrobial resistance. 2015.

3. Gekenidis MT, Qi W, Hummerjohann J, Zbinden R, Walsh F, Drissner D: Antibiotic-resistant indicator bacteria in irrigation water: High prevalence of extended-spectrum beta-lactamase (ESBL)-producing Escherichia coli. PLoS One 2018, 13:e0207857.

4. Mao D, Yu S, Rysz M, Luo Y, Yang F, Li F, Hou J, Mu Q, Alvarez PJ: Prevalence and proliferation of antibiotic resistance genes in two municipal wastewater treatment plants. Water Res 2015, 85:458466.

5. Ng C, Tay M, Tan B, Le TH, Haller L, Chen H, Koh TH, Barkham TMS, Gin KY: Characterization of Metagenomes in Urban Aquatic Compartments Reveals High Prevalence of Clinically Relevant Antibiotic Resistance Genes in Wastewaters. Front Microbiol 2017, 8:2200.

6. Zurfluh K, Hachler H, Nuesch-Inderbinen M, Stephan R: Characteristics of extended-spectrum betalactamase-and carbapenemase-producing Enterobacteriaceae Isolates from rivers and lakes in Switzerland. Appl Environ Microbiol 2013, 79:3021-3026.

7. Berglund B, Fick J, Lindgren PE: Urban wastewater effluent increases antibiotic resistance gene concentrations in a receiving northern European river. Environ Toxicol Chem 2015, 34:192-196.

8. Chen $\mathrm{H}$, Chen $\mathrm{R}$, Jing $\mathrm{L}$, Bai $\mathrm{X}$, Teng $\mathrm{Y}$ : A metagenomic analysis framework for characterization of antibiotic resistomes in river environment: Application to an urban river in Beijing. Environ Pollut 2019, 245:398-407.

9. Hartmann A, Locatelli A, Amoureux L, Depret G, Jolivet C, Gueneau E, Neuwirth C: Occurrence of CTXM Producing Escherichia coli in Soils, Cattle, and Farm Environment in France (Burgundy Region). Front Microbio/ 2012, 3:83.

10. Nascimento T, Cantamessa R, Melo L, Fernandes MR, Fraga E, Dropa M, Sato MIZ, Cerdeira L, Lincopan N: International high-risk clones of Klebsiella pneumoniae KPC-2/CC258 and Escherichia coli CTX-M-15/CC10 in urban lake waters. Sci Total Environ 2017, 598:910-915.

11. Khan FA, Hellmark B, Ehricht R, Soderquist B, Jass J: Related carbapenemase-producing Klebsiella isolates detected in both a hospital and associated aquatic environment in Sweden. Eur J Clin Microbiol Infect Dis 2018, 37:2241-2251. 
12. Teixeira P, Tacao M, Pureza L, Goncalves J, Silva A, Cruz-Schneider MP, Henriques I: Occurrence of carbapenemase-producing Enterobacteriaceae in a Portuguese river: blaNDM, blaKPC and blaGES among the detected genes. Environ Pollut 2020, 260:113913.

13. Proia L, Anzil A, Borrego C, Farre M, Llorca M, Sanchis J, Bogaerts P, Balcazar JL, Servais P: Occurrence and persistence of carbapenemases genes in hospital and wastewater treatment plants and propagation in the receiving river. $J$ Hazard Mater 2018, 358:33-43.

14. Hoelle J, Johnson JR, Johnston BD, Kinkle B, Boczek L, Ryu H, Hayes S: Survey of US wastewater for carbapenem-resistant Enterobacteriaceae. J Water Health 2019, 17:219-226.

15. Makowska N, Philips A, Dabert M, Nowis K, Trzebny A, Koczura R, Mokracka J: Metagenomic analysis of beta-lactamase and carbapenemase genes in the wastewater resistome. Water Res 2020, 170:115277.

16. Sekizuka T, Yatsu K, Inamine Y, Segawa T, Nishio M, Kishi N, Kuroda M: Complete Genome Sequence of a blaKPC-2-Positive Klebsiella pneumoniae Strain Isolated from the Effluent of an Urban Sewage Treatment Plant in Japan. mSphere 2018, 3.

17. Sekizuka T, Inamine Y, Segawa T, Kuroda M: Characterization of NDM-5- and CTX-M-55-coproducing Escherichia coli GSH8M-2 isolated from the effluent of a wastewater treatment plant in Tokyo Bay. Infect Drug Resist 2019, 12:2243-2249.

18. Maheshwari M, Yaser NH, Naz S, Fatima M, Ahmad I: Emergence of ciprofloxacin-resistant extendedspectrum beta-lactamase-producing enteric bacteria in hospital wastewater and clinical sources. $J$ Glob Antimicrob Resist 2016, 5:22-25.

19. Conte D, Palmeiro JK, da Silva Nogueira K, de Lima TM, Cardoso MA, Pontarolo R, Degaut Pontes FL, Dalla-Costa LM: Characterization of CTX-M enzymes, quinolone resistance determinants, and antimicrobial residues from hospital sewage, wastewater treatment plant, and river water. Ecotoxicol Environ Saf 2017, 136:62-69.

20. Lien TQ, Lan PT, Chuc NTK, Hoa NQ, Nhung PH, Thoa NTM, Diwan V, Tamhankar AJ, Stalsby Lundborg C: Antibiotic Resistance and Antibiotic Resistance Genes in Escherichia coli Isolates from Hospital Wastewater in Vietnam. Int J Environ Res Public Health 2017, 14.

21. Basode VK, Abdulhaq A, Alamoudi MUA, Tohari HM, Quhal WA, Madkhali AM, Hobani YH, Hershan AA: Prevalence of a carbapenem-resistance gene (KPC), vancomycin-resistance genes (van A/B) and a methicillin-resistance gene (mecA) in hospital and municipal sewage in a southwestern province of Saudi Arabia. BMC Res Notes 2018, 11:30.

22. Parvez S, Khan AU: Hospital sewage water: a reservoir for variants of New Delhi metallo-betalactamase (NDM)- and extended-spectrum beta-lactamase (ESBL)-producing Enterobacteriaceae. Int $J$ Antimicrob Agents 2018, 51:82-88.

23. Drieux L, Haenn S, Moulin L, Jarlier V: Quantitative evaluation of extended-spectrum beta-lactamaseproducing Escherichia coli strains in the wastewater of a French teaching hospital and relation to patient strain. Antimicrob Resist Infect Control 2016, 5:9. 
24. Lepuschitz S, Schill S, Stoeger A, Pekard-Amenitsch S, Huhulescu S, Inreiter N, Hartl R, Kerschner H, Sorschag S, Springer B, et al: Whole genome sequencing reveals resemblance between ESBLproducing and carbapenem resistant Klebsiella pneumoniae isolates from Austrian rivers and clinical isolates from hospitals. Sci Total Environ 2019, 662:227-235.

25. Novo A, Andre S, Viana P, Nunes OC, Manaia CM: Antibiotic resistance, antimicrobial residues and bacterial community composition in urban wastewater. Water Res 2013, 47:1875-1887.

26. Stalder T, Barraud O, Jove T, Casellas M, Gaschet M, Dagot C, Ploy MC: Quantitative and qualitative impact of hospital effluent on dissemination of the integron pool. Ismej 2014, 8:768-777.

27. Le TH, Ng C, Chen H, Yi XZ, Koh TH, Barkham TM, Zhou Z, Gin KY: Occurrences and Characterization of Antibiotic-Resistant Bacteria and Genetic Determinants of Hospital Wastewater in a Tropical Country. Antimicrob Agents Chemother 2016, 60:7449-7456.

28. Voigt AM, Zacharias N, Timm C, Wasser F, Sib E, Skutlarek D, Parcina M, Schmithausen RM, Schwartz $\mathrm{T}$, Hembach $\mathrm{N}$, et al: Association between antibiotic residues, antibiotic resistant bacteria and antibiotic resistance genes in anthropogenic wastewater - An evaluation of clinical influences. Chemosphere 2020, 241:125032.

29. Lupo A, Coyne S, Berendonk TU: Origin and evolution of antibiotic resistance: the common mechanisms of emergence and spread in water bodies. Front Microbio/ 2012, 3:18.

30. Rodriguez-Mozaz S, Chamorro S, Marti E, Huerta B, Gros M, Sanchez-Melsio A, Borrego CM, Barcelo D, Balcazar JL: Occurrence of antibiotics and antibiotic resistance genes in hospital and urban wastewaters and their impact on the receiving river. Water Res 2015, 69:234-242.

31. Paschoal RP, Campana EH, Correa LL, Montezzi LF, Barrueto LRL, da Silva IR, Bonelli RR, Castro LS, Picao RC: Concentration and Variety of Carbapenemase Producers in Recreational Coastal Waters Showing Distinct Levels of Pollution. Antimicrob Agents Chemother 2017, 61.

32. Mahon BM, Brehony C, McGrath E, Killeen J, Cormican M, Hickey P, Keane S, Hanahoe B, Dolan A, Morris D: Indistinguishable NDM-producing Escherichia coli isolated from recreational waters, sewage, and a clinical specimen in Ireland, 2016 to 2017. Euro Surveill 2017, 22.

33. O'Flaherty E, Borrego CM, Balcazar JL, Cummins E: Human exposure assessment to antibioticresistant Escherichia coli through drinking water. Sci Total Environ 2018, 616-617:1356-1364.

34. Said LB, Hamdaoui M, Jouini A, Boudabous A, Slama KB, Torres C, Klibi N: First Detection of CTX-M-1 in Extended-Spectrum beta-Lactamase-Producing Escherichia coli in Seafood from Tunisia. $J$ Food Prot 2017:1877-1881.

35. Sanjit Singh A, Lekshmi M, Prakasan S, Nayak BB, Kumar S: Multiple Antibiotic-Resistant, Extended Spectrum-beta-Lactamase (ESBL)-Producing Enterobacteria in Fresh Seafood. Microorganisms 2017, 5.

36. Mani Y, Mansour W, Lupo A, Saras E, Bouallegue O, Madec JY, Haenni M: Spread of blaCTX-M-15Producing Enterobacteriaceae and OXA-23-Producing Acinetobacter baumannii Sequence Type 2 in Tunisian Seafood. Antimicrob Agents Chemother 2018, 62. 
37. Vu TTT, Alter T, Roesler U, Roschanski N, Huehn S: Investigation of Extended-Spectrum and AmpC beta-Lactamase-Producing Enterobacteriaceae from Retail Seafood in Berlin, Germany. J Food Prot 2018, 81:1079-1086.

38. Zhang A, Call DR, Besser TE, Liu J, Jones L, Wang H, Davis MA: beta-lactam resistance genes in bacteriophage and bacterial DNA from wastewater, river water, and irrigation water in Washington State. Water Res 2019, 161:335-340.

39. Potter RF, D'Souza AW, Dantas G: The rapid spread of carbapenem-resistant Enterobacteriaceae. Drug Resist Updat 2016, 29:30-46.

40. Tzouvelekis LS, Markogiannakis A, Piperaki E, Souli M, Daikos GL: Treating infections caused by carbapenemase-producing Enterobacteriaceae. Clin Microbiol Infect 2014, 20:862-872.

41. Tamma PD, Goodman KE, Harris AD, Tekle T, Roberts A, Taiwo A, Simner PJ: Comparing the Outcomes of Patients With Carbapenemase-Producing and Non-Carbapenemase-Producing Carbapenem-Resistant Enterobacteriaceae Bacteremia. Clin Infect Dis 2017, 64:257-264.

42. Soontaros S, Leelakanok N: Association between carbapenem-resistant Enterobacteriaceae and death: A systematic review and meta-analysis. Am J Infect Control 2019, 47:1200-1212.

43. Lamba M, Gupta S, Shukla R, Graham DW, Sreekrishnan TR, Ahammad SZ: Carbapenem resistance exposures via wastewaters across New Delhi. Environ Int 2018, 119:302-308.

44. Montezzi LF, Campana EH, Correa LL, Justo LH, Paschoal RP, da Silva IL, Souza Mdo C, Drolshagen $\mathrm{M}$, Picao RC: Occurrence of carbapenemase-producing bacteria in coastal recreational waters. Int $\mathrm{J}$ Antimicrob Agents 2015, 45:174-177.

45. Zhuang Y, Ren H, Geng J, Zhang Y, Zhang Y, Ding L, Xu K: Inactivation of antibiotic resistance genes in municipal wastewater by chlorination, ultraviolet, and ozonation disinfection. Environ Sci Pollut Res Int 2015, 22:7037-7044.

46. Wu J, Cheng S, Cai MH, Wu YP, Li Y, Wu JC, Li AM, Li WT: Applying UV absorbance and fluorescence indices to estimate inactivation of bacteria and formation of bromate during ozonation of water and wastewater effluent. Water Res 2018, 145:354-364.

47. Jager T, Hembach N, Elpers C, Wieland A, Alexander J, Hiller C, Krauter G, Schwartz T: Reduction of Antibiotic Resistant Bacteria During Conventional and Advanced Wastewater Treatment, and the Disseminated Loads Released to the Environment. Front Microbio/ 2018, 9:2599.

48. Alexander J, Knopp G, Dotsch A, Wieland A, Schwartz T: Ozone treatment of conditioned wastewater selects antibiotic resistance genes, opportunistic bacteria, and induce strong population shifts. Sci Total Environ 2016, 559:103-112.

49. Liu SS, Qu HM, Yang D, Hu H, Liu WL, Qiu ZG, Hou AM, Guo J, Li JW, Shen ZQ, Jin M: Chlorine disinfection increases both intracellular and extracellular antibiotic resistance genes in a full-scale wastewater treatment plant. Water Res 2018, 136:131-136.

50. Paulus GK, Hornstra LM, Alygizakis N, Slobodnik J, Thomaidis N, Medema G: The impact of on-site hospital wastewater treatment on the downstream communal wastewater system in terms of antibiotics and antibiotic resistance genes. Int J Hyg Environ Health 2019, 222:635-644. 
51. Shen $Y$, Zhuan $R$, Chu L, Xiang $X$, Sun $H$, Wang J: Inactivation of antibiotic resistance genes in antibiotic fermentation residues by ionizing radiation: Exploring the development of recycling economy in antibiotic pharmaceutical factory. Waste Manag 2019, 84:141-146.

52. Takeuchi F, Sekizuka T, Yamashita A, Ogasawara Y, Mizuta K, Kuroda M: MePIC, metagenomic pathogen identification for clinical specimens. Jpn J Infect Dis 2014, 67:62-65.

53. Ondov BD, Bergman NH, Phillippy AM: Interactive metagenomic visualization in a Web browser. $B M C$ Bioinformatics 2011, 12:385.

54. Huson DH, Beier S, Flade I, Gorska A, El-Hadidi M, Mitra S, Ruscheweyh HJ, Tappu R: MEGAN Community Edition - Interactive Exploration and Analysis of Large-Scale Microbiome Sequencing Data. PLoS Comput Biol 2016, 12:e1004957.

55. Larsen MV, Cosentino S, Rasmussen S, Friis C, Hasman H, Marvig RL, Jelsbak L, Sicheritz-Ponten T, Ussery DW, Aarestrup FM, Lund O: Multilocus sequence typing of total-genome-sequenced bacteria. $J$ Clin Microbio/ 2012, 50:1355-1361.

56. Zankari E, Hasman H, Cosentino S, Vestergaard M, Rasmussen S, Lund O, Aarestrup FM, Larsen MV: Identification of acquired antimicrobial resistance genes. J Antimicrob Chemother 2012, 67:26402644.

57. Li H, Durbin R: Fast and accurate long-read alignment with Burrows-Wheeler transform. Bioinformatics 2010, 26:589-595.

58. Koboldt DC, Chen K, Wylie T, Larson DE, McLellan MD, Mardis ER, Weinstock GM, Wilson RK, Ding L: VarScan: variant detection in massively parallel sequencing of individual and pooled samples. Bioinformatics 2009, 25:2283-2285.

59. Arndt D, Grant JR, Marcu A, Sajed T, Pon A, Liang Y, Wishart DS: PHASTER: a better, faster version of the PHAST phage search tool. Nucleic Acids Res 2016, 44:W16-21.

60. Kurtz S, Phillippy A, Delcher AL, Smoot M, Shumway M, Antonescu C, Salzberg SL: Versatile and open software for comparing large genomes. Genome Biol 2004, 5:R12.

61. Croucher NJ, Page AJ, Connor TR, Delaney AJ, Keane JA, Bentley SD, Parkhill J, Harris SR: Rapid phylogenetic analysis of large samples of recombinant bacterial whole genome sequences using Gubbins. Nucleic Acids Res 2015, 43:e15.

62. Souvorov A, Agarwala R, Lipman DJ: SKESA: strategic k-mer extension for scrupulous assemblies. Genome Biol 2018, 19:153.

63. Joensen KG, Tetzschner AM, Iguchi A, Aarestrup FM, Scheutz F: Rapid and Easy In Silico Serotyping of Escherichia coli Isolates by Use of Whole-Genome Sequencing Data. J Clin Microbio/ 2015, 53:2410-2426.

64. Narumiya M, Nakada N, Yamashita N, Tanaka H: Phase distribution and removal of pharmaceuticals and personal care products during anaerobic sludge digestion. J Hazard Mater 2013, 260:305-312.

65. Janda JM, Abbott SL: The genus Aeromonas: taxonomy, pathogenicity, and infection. Clin Microbiol Rev 2010, 23:35-73. 
66. Nishijima S, Suda W, Oshima K, Kim SW, Hirose Y, Morita H, Hattori M: The gut microbiome of healthy Japanese and its microbial and functional uniqueness. DNA Res 2016, 23:125-133.

67. Chen YL, Wang CH, Yang FC, Ismail W, Wang PH, Shih CJ, Wu YC, Chiang YR: Identification of Comamonas testosteroni as an androgen degrader in sewage. Sci Rep 2016, 6:35386.

68. Merga JY, Royden A, Pandey AK, Williams NJ: Arcobacter spp. isolated from untreated domestic effluent. Lett App/ Microbiol 2014, 59:122-126.

69. Webb AL, Taboada EN, Selinger LB, Boras VF, Inglis GD: Prevalence and diversity of waterborne Arcobacter butzleri in southwestern Alberta, Canada. Can J Microbio/ 2017, 63:330-340.

70. Millar JA, Raghavan R: Accumulation and expression of multiple antibiotic resistance genes in Arcobacter cryaerophilus that thrives in sewage. PeerJ 2017, 5:e3269.

71. Ghaju Shrestha R, Sherchan SP, Kitajima M, Tanaka Y, Gerba CP, Haramoto E: Reduction of Arcobacter at Two Conventional Wastewater Treatment Plants in Southern Arizona, USA. Pathogens 2019, 8.

72. Ferreira S, Luis A, Oleastro M, Pereira L, Domingues FC: A meta-analytic perspective on Arcobacter spp. antibiotic resistance. J Glob Antimicrob Resist 2019, 16:130-139.

73. Lee K, Izumiya H, lyoda S, Ohnishi M: Effective Surveillance Using Multilocus Variable-Number Tandem-Repeat Analysis and Whole-Genome Sequencing for Enterohemorrhagic Escherichia coli 0157. Appl Environ Microbiol 2019, 85.

74. Arpin C, Quentin C, Grobost F, Cambau E, Robert J, Dubois V, Coulange L, Andre C, ScientifiC Committee of $\mathrm{O}$ : Nationwide survey of extended-spectrum \{beta\}-lactamase-producing Enterobacteriaceae in the French community setting. J Antimicrob Chemother 2009, 63:1205-1214.

75. Bevan ER, Jones AM, Hawkey PM: Global epidemiology of CTX-M beta-lactamases: temporal and geographical shifts in genotype. J Antimicrob Chemother 2017, 72:2145-2155.

76. Harris PNA, Ben Zakour NL, Roberts LW, Wailan AM, Zowawi HM, Tambyah PA, Lye DC, Jureen R, Lee $\mathrm{TH}$, Yin M, et al: Whole genome analysis of cephalosporin-resistant Escherichia coli from bloodstream infections in Australia, New Zealand and Singapore: high prevalence of CMY-2 producers and ST131 carrying blaCTX-M-15 and blaCTX-M-27. J Antimicrob Chemother 2018, 73:634-642.

77. Noguchi T, Matsumura Y, Kanahashi T, Tanaka M, Tsuchido Y, Matsumura T, Nakano S, Yamamoto M, Nagao M, Ichiyama S: Role of TEM-1 beta-Lactamase in the Predominance of AmpicillinSulbactam-Nonsusceptible Escherichia coli in Japan. Antimicrob Agents Chemother 2019, 63.

78. Higa S, Sarassari R, Hamamoto K, Yakabi Y, Higa K, Koja Y, Hirai I: Characterization of CTX-M type ESBL-producing Enterobacteriaceae isolated from asymptomatic healthy individuals who live in a community of the Okinawa prefecture, Japan. $J$ Infect Chemother 2019, 25:314-317.

79. Nakane K, Kawamura K, Goto K, Arakawa Y: Long-Term Colonization by bla(CTX-M)-Harboring Escherichia coli in Healthy Japanese People Engaged in Food Handling. App/ Environ Microbiol 2016, 82:1818-1827. 
80. Luvsansharav UO, Hirai I, Niki M, Nakata A, Yoshinaga A, Moriyama T, Yamamoto Y: Prevalence of fecal carriage of extended-spectrum beta-lactamase-producing Enterobacteriaceae among healthy adult people in Japan. $J$ Infect Chemother 2011, 17:722-725.

81. Hayakawa K, Nakano R, Hase R, Shimatani M, Kato H, Hasumi J, Doi A, Sekiya N, Nei T, Okinaka K, et al: Comparison between IMP carbapenemase-producing Enterobacteriaceae and noncarbapenemase-producing Enterobacteriaceae: a multicentre prospective study of the clinical and molecular epidemiology of carbapenem-resistant Enterobacteriaceae. J Antimicrob Chemother 2019.

82. Zhao WH, Chen G, Ito R, Kimura S, Hu ZQ: Identification of a plasmid-borne blalMP-11 gene in clinical isolates of Escherichia coli and Klebsiella pneumoniae. J Med Microbiol 2012, 61:246-251.

83. Mano Y, Saga T, Ishii Y, Yoshizumi A, Bonomo RA, Yamaguchi K, Tateda K: Molecular analysis of the integrons of metallo-beta-lactamase-producing Pseudomonas aeruginosa isolates collected by nationwide surveillance programs across Japan. BMC Microbio/ 2015, 15:41.

84. Yamamoto M, Nagao M, Matsumura Y, Hotta G, Matsushima A, Ito Y, Takakura S, Ichiyama S: Regional dissemination of Acinetobacter species harbouring metallo-beta-lactamase genes in Japan. Clin Microbiol Infect 2013, 19:729-736.

85. Remold SK, Brown CK, Farris JE, Hundley TC, Perpich JA, Purdy ME: Differential habitat use and niche partitioning by Pseudomonas species in human homes. Microb Ecol 2011, 62:505-517.

86. Elomari M, Coroler L, Verhille S, Izard D, Leclerc H: Pseudomonas monteilii sp. nov., isolated from clinical specimens. Int J Syst Bacteriol 1997, 47:846-852.

87. Ocampo-Sosa AA, Guzman-Gomez LP, Fernandez-Martinez M, Roman E, Rodriguez C, Marco F, Vila J, Martinez-Martinez L: Isolation of VIM-2-producing Pseudomonas monteilii clinical strains disseminated in a tertiary hospital in northern Spain. Antimicrob Agents Chemother 2015, 59:13341336.

88. Aditi, Shariff M, Beri K: Exacerbation of bronchiectasis by Pseudomonas monteilii: a case report. BMC Infect Dis 2017, 17:511.

89. Scotta C, Juan C, Cabot G, Oliver A, Lalucat J, Bennasar A, Alberti S: Environmental microbiota represents a natural reservoir for dissemination of clinically relevant metallo-beta-lactamases. Antimicrob Agents Chemother 2011, 55:5376-5379.

90. Bogaerts P, Bouchahrouf W, Lissoir B, Denis O, Glupczynski Y: IMP-13-producing Pseudomonas monteilii recovered in a hospital environment. J Antimicrob Chemother 2011, 66:2434-2435.

91. Wiest L, Chonova T, Berge A, Baudot R, Bessueille-Barbier F, Ayouni-Derouiche L, Vulliet E: Two-year survey of specific hospital wastewater treatment and its impact on pharmaceutical discharges. Environ Sci Pollut Res Int 2018, 25:9207-9218.

92. Santos LH, Gros M, Rodriguez-Mozaz S, Delerue-Matos C, Pena A, Barcelo D, Montenegro MC: Contribution of hospital effluents to the load of pharmaceuticals in urban wastewaters: identification of ecologically relevant pharmaceuticals. Sci Total Environ 2013, 461-462:302-316.

93. Li D, Yang M, Hu J, Zhang Y, Chang H, Jin F: Determination of penicillin $\mathbf{G}$ and its degradation products in a penicillin production wastewater treatment plant and the receiving river. Water Res 
2008, 42:307-317.

94. Zhou LJ, Ying GG, Liu S, Zhao JL, Yang B, Chen ZF, Lai HJ: Occurrence and fate of eleven classes of antibiotics in two typical wastewater treatment plants in South China. Sci Total Environ 2013, 452453:365-376.

95. Gaspar A, Andrasi M, Kardos S: Application of capillary zone electrophoresis to the analysis and to a stability study of cephalosporins. J Chromatogr B Analyt Technol Biomed Life Sci 2002, 775:239246.

96. Coutu S, Rossi L, Barry DA, Rudaz S, Vernaz N: Temporal variability of antibiotics fluxes in wastewater and contribution from hospitals. PLoS One 2013, 8:e53592.

97. Kummerer $\mathrm{K}$, Henninger $\mathrm{A}$ : Promoting resistance by the emission of antibiotics from hospitals and households into effluent. Clin Microbiol Infect 2003, 9:1203-1214.

98. Buelow E, Bayjanov JR, Majoor E, Willems RJ, Bonten MJ, Schmitt $H$, van Schaik W: Limited influence of hospital wastewater on the microbiome and resistome of wastewater in a community sewerage system. FEMS Microbiol Ecol 2018, 94.

99. Gullberg E, Cao S, Berg OG, Ilback C, Sandegren L, Hughes D, Andersson DI: Selection of resistant bacteria at very low antibiotic concentrations. PLoS Pathog 2011, 7:e1002158.

100. Andersson DI, Hughes D: Evolution of antibiotic resistance at non-lethal drug concentrations. Drug Resist Updat 2012, 15:162-172.

101. Jutkina J, Rutgersson C, Flach CF, Joakim Larsson DG: An assay for determining minimal concentrations of antibiotics that drive horizontal transfer of resistance. Sci Total Environ 2016, 548549:131-138.

102. Lien LT, Hoa NQ, Chuc NT, Thoa NT, Phuc HD, Diwan V, Dat NT, Tamhankar AJ, Lundborg CS: Antibiotics in Wastewater of a Rural and an Urban Hospital before and after Wastewater Treatment, and the Relationship with Antibiotic Use-A One Year Study from Vietnam. Int J Environ Res Public Health 2016, 13.

103. Goren MG, Carmeli Y, Schwaber MJ, Chmelnitsky I, Schechner V, Navon-Venezia S: Transfer of carbapenem-resistant plasmid from Klebsiella pneumoniae ST258 to Escherichia coli in patient. Emerg Infect Dis 2010, 16:1014-1017.

104. Bengtsson-Palme J, Kristiansson E, Larsson DGJ: Environmental factors influencing the development and spread of antibiotic resistance. FEMS Microbiol Rev 2018, 42.

105. Mach PA, Grimes DJ: R-plasmid transfer in a wastewater treatment plant. App/ Environ Microbiol 1982, 44:1395-1403.

106. Krzeminski P, Schwermer C, Wennberg A, Langford K, Vogelsang C: Occurrence of UV filters, fragrances and organophosphate flame retardants in municipal WWTP effluents and their removal during membrane post-treatment. J Hazard Mater 2017, 323:166-176.

107. Mathys DA, Mollenkopf DF, Feicht SM, Adams RJ, Albers AL, Stuever DM, Grooters SV, Ballash GA, Daniels JB, Wittum TE: Carbapenemase-producing Enterobacteriaceae and Aeromonas spp. present 
in wastewater treatment plant effluent and nearby surface waters in the US. PLOS One 2019, 14:e0218650.

108. Hembach N, Alexander J, Hiller C, Wieland A, Schwartz T: Dissemination prevention of antibiotic resistant and facultative pathogenic bacteria by ultrafiltration and ozone treatment at an urban wastewater treatment plant. Sci Rep 2019, 9:12843.

109. Okubo T, Hasegawa T, Fukuda A, Thapa J, Usui M, Tamura Y, Yamaguchi H: Screening of hospitalmanhole sewage using MacConkey agar with cefotaxime reveals extended-spectrum beta-lactamase (ESBL)-producing Escherichia coli. Int J Antimicrob Agents 2019, 54:831-833.

110. Azuma T, Otomo K, Kunitou M, Shimizu M, Hosomaru K, Mikata S, Ishida M, Hisamatsu K, Yunoki A, Mino $Y$, Hayashi $T$ : Environmental fate of pharmaceutical compounds and antimicrobial-resistant bacteria in hospital effluents, and contributions to pollutant loads in the surface waters in Japan. Sci Total Environ 2019, 657:476-484.

111. Huijbers PM, Blaak H, de Jong MC, Graat EA, Vandenbroucke-Grauls CM, de Roda Husman AM: Role of the Environment in the Transmission of Antimicrobial Resistance to Humans: A Review. Environ Sci Technol 2015, 49:11993-12004.

\section{Tables}


Table 1. Bacteria isolates growing on CHROMagar ESBL

\begin{tabular}{|c|c|c|c|}
\hline \multirow{2}{*}{ Bacteria species } & \multicolumn{2}{|c|}{ Hospital sewage tank } & \multirow{2}{*}{ Clinical isolate ${ }^{c}$} \\
\hline & STW0522a & STN0717b & \\
\hline Escherichia coli & 1 & 20 & 16 \\
\hline Klebsiella pneumoniae & 2 & & 3 \\
\hline Klebsiella aerogenes & & 1 & \\
\hline Klebsiella michiganensis & & & 1 \\
\hline Klebsiella quasipneumoniae & 1 & & \\
\hline Klebsiella variicola & 1 & & \\
\hline Klebsiella sp. & 2 & & \\
\hline Enterobacter kobei & 21 & 2 & \\
\hline Enterobacter bugandensis & & 12 & \\
\hline Enterobacter hormaechei & 3 & 1 & \\
\hline Enterobacter cloacae & & 3 & \\
\hline Enterobacter roggenkampii & 1 & & \\
\hline Citrobacter portucalensis & 16 & 39 & \\
\hline Citrobacter freundii & 20 & & \\
\hline Achromobacter xylosoxidans & 5 & & \\
\hline Pseudomonas monteilii & 3 & & \\
\hline Raoultella planticola & 1 & & \\
\hline Stenotrophomonas maltophilia & 1 & & \\
\hline
\end{tabular}

aSTW0522: sewage tank of west building at 22, May, 2018

bSTN0717: sewage tank of new building at 17, July, 2018.

${ }^{\mathrm{C}}$ Clinical isolate: patients from 8, May 2018 to 17, July 2018 
Table 2. Serotype of ESBL-producing E.coli in sewage and clinical isolate

\begin{tabular}{|c|c|c|c|c|c|}
\hline \multirow[b]{2}{*}{ Sequence type } & \multirow[b]{2}{*}{ Serotype } & \multicolumn{2}{|c|}{ Hospital sewage tank } & \multirow{2}{*}{ Clinical } & \multirow{2}{*}{ isolate $^{c}$} \\
\hline & & STW $0522^{a}$ & STN $0717^{b}$ & & \\
\hline ST12 & $\mathrm{O} 4: \mathrm{H} 1$ & & & & 1 \\
\hline ST38 & O86:H18 & & 5 & & 3 \\
\hline ST73 & O6:H1 & & & & 1 \\
\hline ST131 & $\mathrm{O} 25: \mathrm{H} 4$ & & & & 5 \\
\hline ST224 & O8:H23 & 1 & & & \\
\hline ST393 & O15:H1 & & 14 & & 2 \\
\hline ST1011 & O130:H10 & & & & 4 \\
\hline ST9586 & O8:H10 & & 1 & & \\
\hline
\end{tabular}

asTW0522; sewage tank of west building at 22, May 2018

bSTN0717; sewage tank of new building at 17, July, 2018.

${ }^{\mathrm{C}}$ Clinically isolate; clinically isolate from 8, May 2018 to 17,July 2018 
Table 3. ESBL-producer in hospital sewage and clinical isolate

\begin{tabular}{|c|c|c|c|c|c|}
\hline \multirow[b]{2}{*}{ Bacteria } & \multirow{2}{*}{ Antimicrobial resistant gene (ARG) } & \multicolumn{2}{|c|}{ Hospital sewage tank } & \multirow{2}{*}{ Clinical } & \multirow{2}{*}{ isolate $^{\mathrm{c}}$} \\
\hline & & STW $0522^{\mathrm{a}}$ & STN $0717^{\mathrm{b}}$ & & \\
\hline \multicolumn{6}{|c|}{ Escherichia coli } \\
\hline & blaCTX-M-14 & 1 & & & 4 \\
\hline & blaCTX-M-15 & & & & 2 \\
\hline & blaCTX-M-27 & & 14 & & 6 \\
\hline & blaCTX-M-44 & & & & 1 \\
\hline & blaCTX-M-55 & & 6 & & 4 \\
\hline \multicolumn{6}{|c|}{ Klebsiella pneumoniae } \\
\hline & blaCTX-M-14 & & & & 2 \\
\hline & blaCTX-M-15 & & & & 1 \\
\hline & blaCTX-M-2 & 2 & & & \\
\hline & blaSHV-26 & 2 & & & \\
\hline & blaSHV-77 & & & & 1 \\
\hline & blaSHV-78 & & & & 2 \\
\hline
\end{tabular}

Klebsiella quasipneumoniae

blaCTX-M-2 1

Klebsiella variicola

blaCTX-M-62 1

Klebsiella michiganensis

blaCTX-M-8

Klebsiella sp.

blaCTX-M-5 2

Enterobacter cloacae

blaSHV-12

Enterobacter kobei

blaCTX-M-14 5

blaCTX-M-62 1

blaSHV-12 2 
Enterobacter hormaechei

blaCTX-M-9

Pseudomonas monteilii

blaIMP-11

Raoultella planticola

blaSHV-12

1

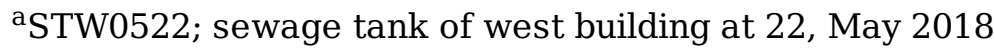

bSTN0717; sewage tank of new building at 17, July, 2018.

${ }^{\mathrm{c} C l i n i c a l}$ isolate; clinical isolate from 8, May 2018 to 17,July 2018 
Table 4. Concentrations of chemical compounds in the hospital sewage tank

\begin{tabular}{|c|c|c|c|}
\hline \multirow[b]{2}{*}{ Antimicrobials and others } & \multicolumn{2}{|c|}{ Concentration (ng/L) } & \multirow[b]{2}{*}{ Note } \\
\hline & STN0717 $7^{\mathrm{ab}}$ & Limit of quantity & \\
\hline \multicolumn{4}{|l|}{ Quinolone } \\
\hline Levofloxacin & 32500 & 5.00 & clinical \\
\hline Norfloxacin & n.d. & 1.00 & clinical \\
\hline Enrofloxacin & n.d. & 2.00 & veterinary \\
\hline \multicolumn{4}{|l|}{ Macrolide/lincosamide } \\
\hline Azithromycin & 390 & 0.01 & clinical \\
\hline Clarithromycin & 13500 & 0.10 & clinical \\
\hline Lincomycin & 370 & 0.05 & clinical \\
\hline Roxithromycin & n.d. & 10.00 & clinical \\
\hline \multicolumn{4}{|l|}{ Sulfonamides } \\
\hline Sulfamethoxazole & 1360 & 20.00 & clinical \\
\hline Sulfadimethoxine & n.d. & 0.04 & veterinary \\
\hline \multicolumn{4}{|l|}{ Trimethoprim } \\
\hline Trimethoprim & 1160 & 5.00 & clinical \\
\hline \multicolumn{4}{|l|}{ Tetracycline } \\
\hline Tetracycline & n.d. & 0.70 & clinical \\
\hline Oxytetracycline & n.d. & 3.00 & veterinary \\
\hline \multicolumn{4}{|l|}{ Other clinicals } \\
\hline \multicolumn{4}{|l|}{ Antihypertensive } \\
\hline Valsartan & 6670 & 20.00 & angiotensin $\square$ receptor antagonist \\
\hline Telmisartan & 6010 & 100.00 & angiotensin $\square$ receptor antagonist \\
\hline Olmesartan & 1890 & 0.10 & angiotensin $\square$ receptor antagonist \\
\hline Irbesartan & 1470 & 10.00 & angiotensin $\square$ receptor antagonist \\
\hline Losartan & 1350 & 0.15 & angiotensin $\square$ receptor antagonist \\
\hline Candesartan & 681 & 5.00 & angiotensin $\square$ receptor antagonist \\
\hline Azilsartan & 167 & 20.00 & angiotensin $\square$ receptor antagonist \\
\hline Valsartan acid & 140 & 5.00 & angiotensin $\square$ receptor antagonist \\
\hline Atenolol & 1020 & 5.00 & $\beta$-blocker \\
\hline Atenolol acid & 280 & 0.82 & $\beta$-blocker \\
\hline Metoprolol & 30 & 5.00 & Adrenergic effect blocker \\
\hline Diltiazem & 210 & 0.03 & Vasodilators \\
\hline \multicolumn{4}{|l|}{ Anti-allergic drug } \\
\hline Fexofenadine & 7440 & 5.00 & H1 receptor antagonist \\
\hline Diphenhydramine & 340 & 0.06 & H1 receptor antagonist \\
\hline
\end{tabular}


Epinastine

Caffeine

Caffeine

Bronchodilator

Theophylline

Non-steroidal anti-inflammatory analgesic

Ibuprofen

Ketoprofen

Ethenzamide

Gastric secretion inhibitor

Pirenzepine

Antipsychotic drug

Quetiapine fumarate

Sulpiride

Hyperlipemia drug

Bezafibrate

Antiarrhythmic drug

Disopyramide

Vasodilator drug

Dipyridamole

Diuretic

Furosemide
2520

27

38100

14200

2180

40

70

20

2820

9760

2650

190

7510
$10.00 \quad$ H1 receptor antagonist

10.00 xanthine derivative

0.10 xanthine derivative

39.00 propionic acid

10.00 propionic acid

8.24 Salicylic acid

0.03 Muscarinic receptor antagonist

0.05 Dibenzothiazepine

0.05 Benzamide

10.00 Hyperlipidemic agent

0.09 Antiarrhythmic drug

5.00 Antiplatelet drug

aSTN0717; sewage tank of new building at 17, July 2018

${ }^{b}$ n.d; not detected

\section{Figures}




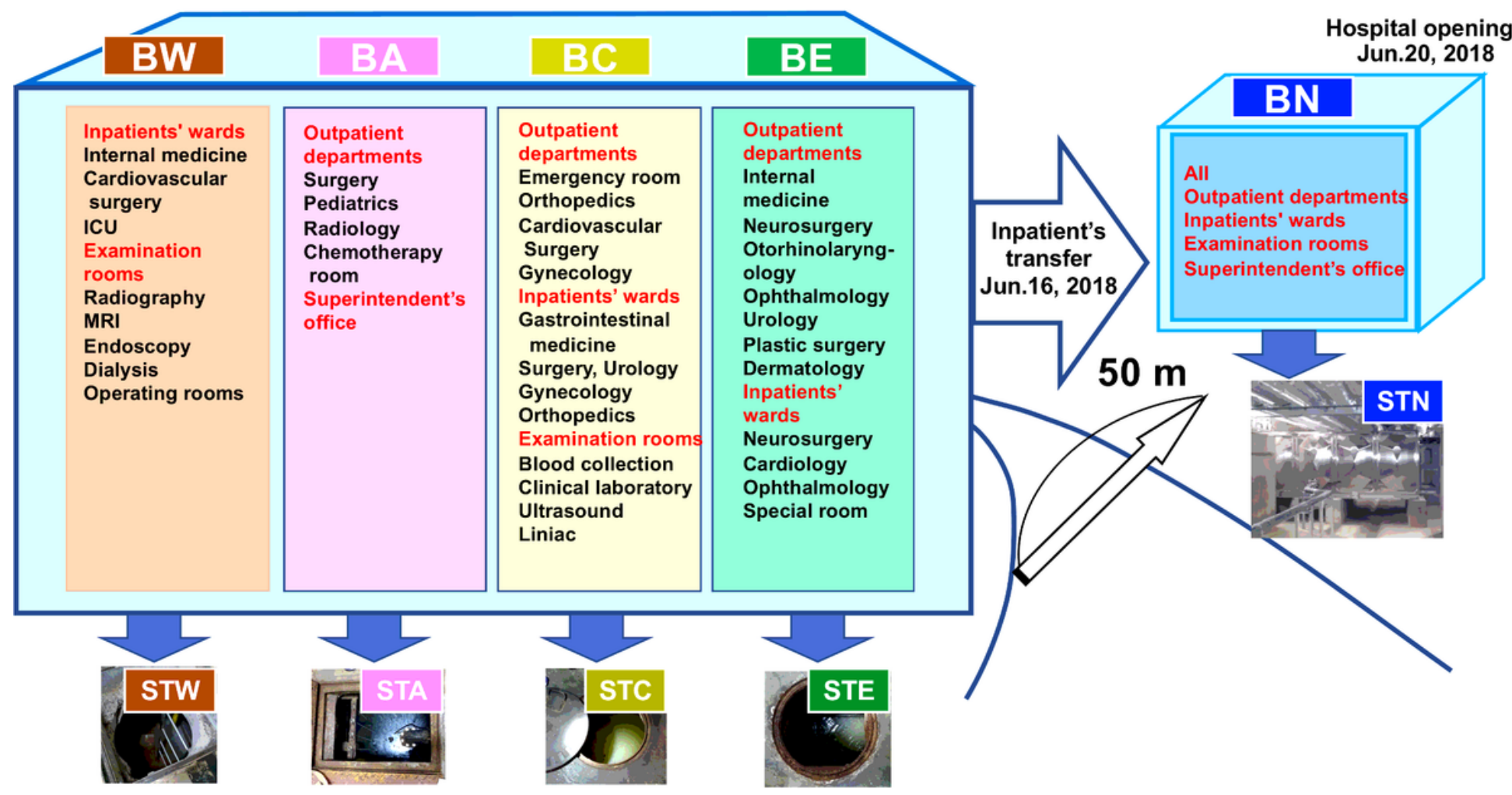

Figure 1

Outline of the Ohashi Medical Center, Toho University. Prior to relocation to the new building (BN), the hospital consisted of four buildings: West building (BW), Administration building (BA), Central building $(\mathrm{BC})$, and East building (BE).

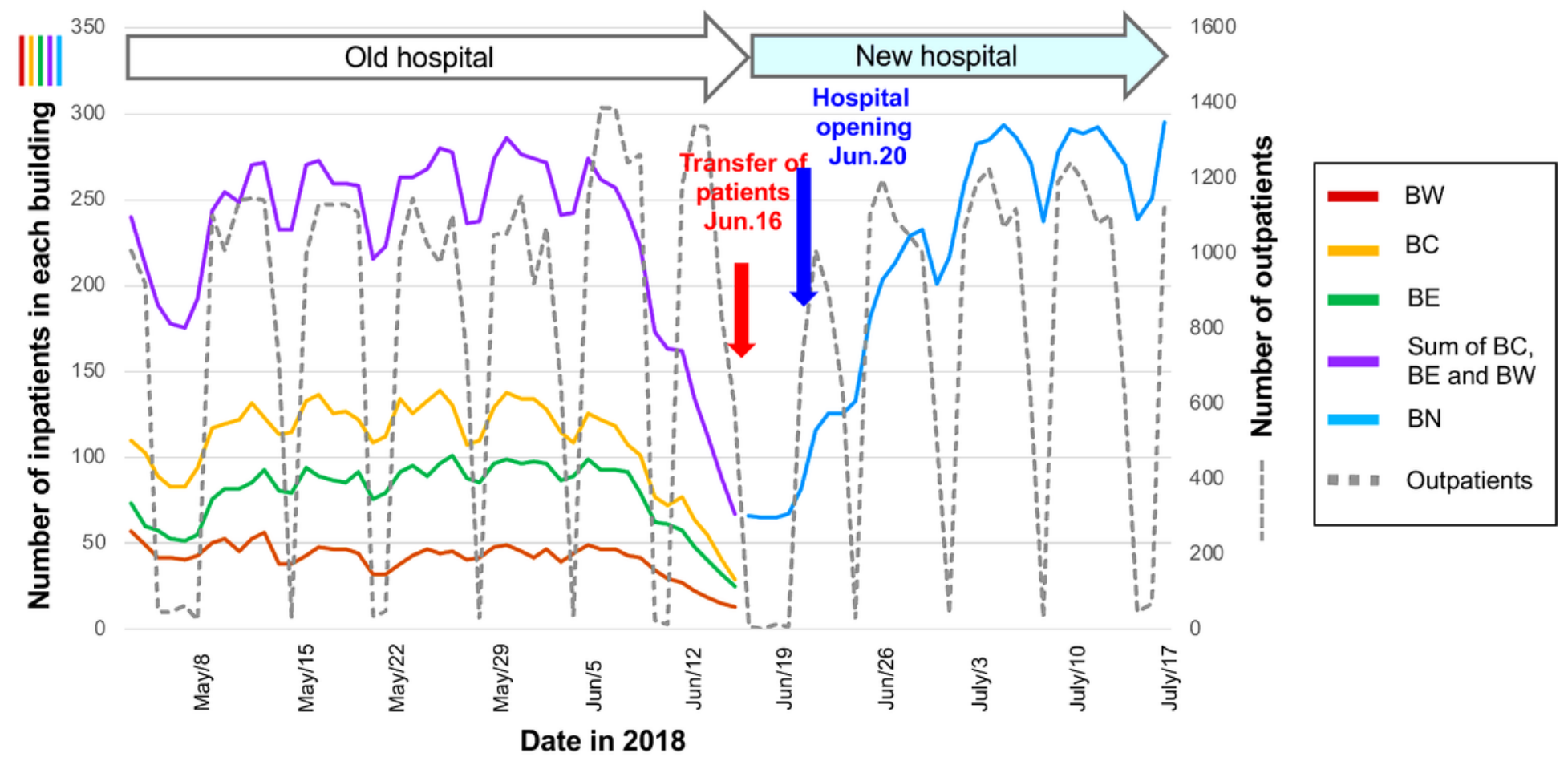

Figure 2 
Graph represents the transition of the number of outpatients and hospitalized patients from May 1 to July 17,2018 . The number of beds were $65,0,148,106$, and 319 for BW, BA, BC, BE, and BN, respectively. In June 2018, due to the inauguration of the new hospital, the number of hospitalized patients gradually decreased, and 67 hospitalized patients (BC: 29, BE: 25, BW: 13 patients) were transferred to the BN on June 16,2018 . The number of hospitalized patients recovered to as same as the number of patients in old hospital two weeks after the new hospital opening. The number of outpatients at the old hospital was approximately 1000-1200 on weekdays. Outpatient treatment was suspended from June 16 to 19 before opening of the new hospital, subsequently the number of patients gradually recovered to the number.
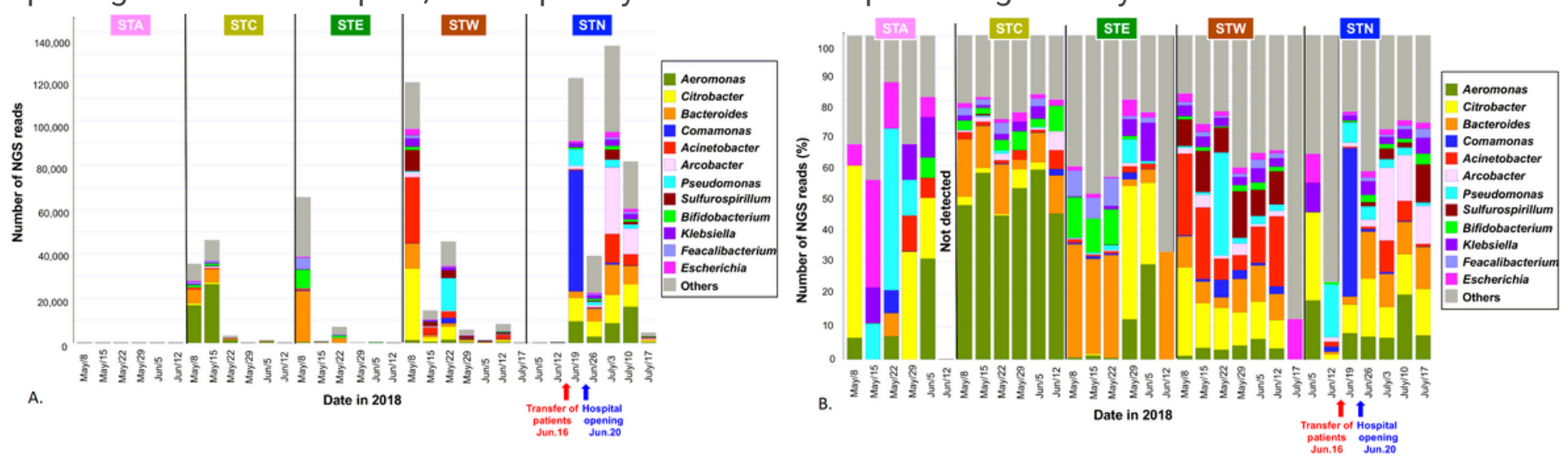

Figure 3

Metagenomic analysis of sewage samples in each building. NGS reads were classified based on the bacterial genus taxonomy and the graph displayed actual NGS read counts (a) and relative proportion (b) of each bacterial genus. In sewage tank of BA (STA), actual NGS read counts were very low compared with other sewage samples. 


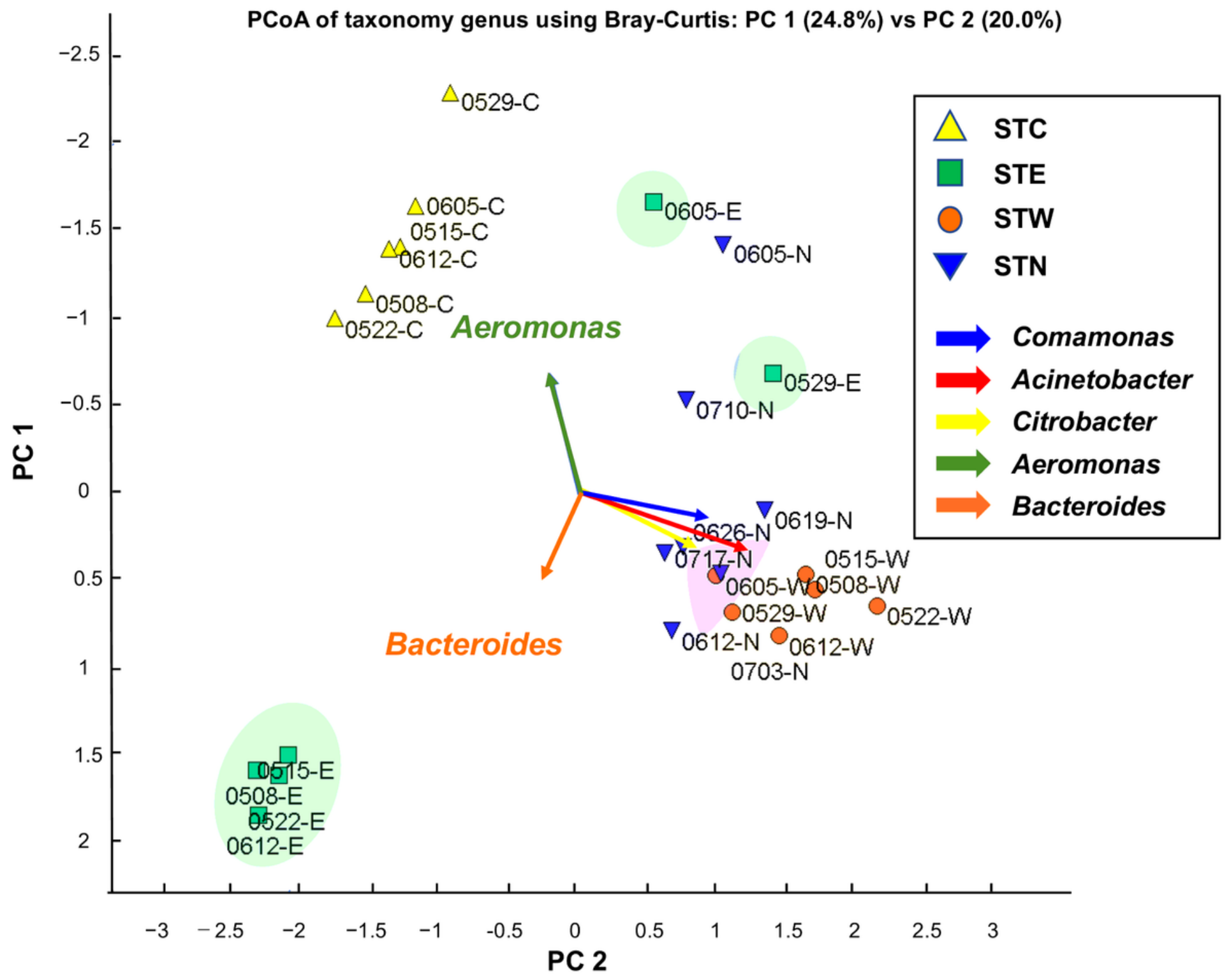

Figure 4

PCoA plot using detected NGS read counts by metagenome DNA-Seq. PCoA was performed according to Bray Curtis distance (the average linkage). The genera, Acinetobacter, Citrobacter, and Comamonas were common present in STW and STN samples. Most severely ill inpatients were treated in the BW and BN, thus their excretion may have a major impact on the bacterial content of the sewage tanks.

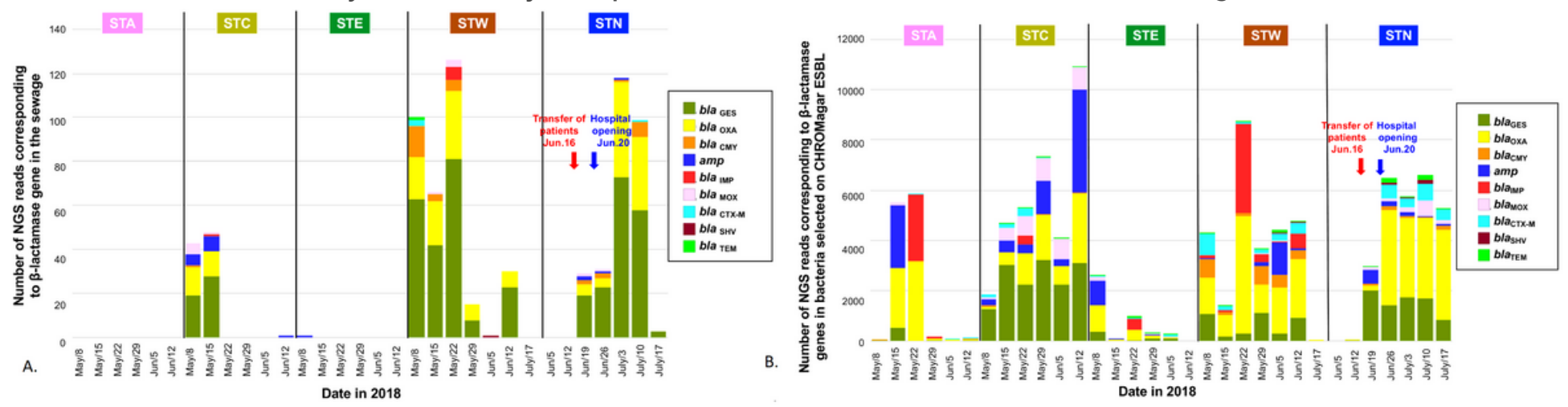




\section{Figure 5}

NGS read counts corresponding to $\beta$-lactamase genes in each sewage tank. The metagenome read counts corresponding to $\beta$-lactamase gene of (a) the sewage samples and (b) that of the grown bacteria on CHROMagar ESBL is displayed. The read counts of blaCTX-M gene in original sewages were not significant (panel a), but selection on CHROMagar ESBL resulted in increasing detection of CTX-Mpositive organisms in STN, after relocation to new building (June 20,2018).

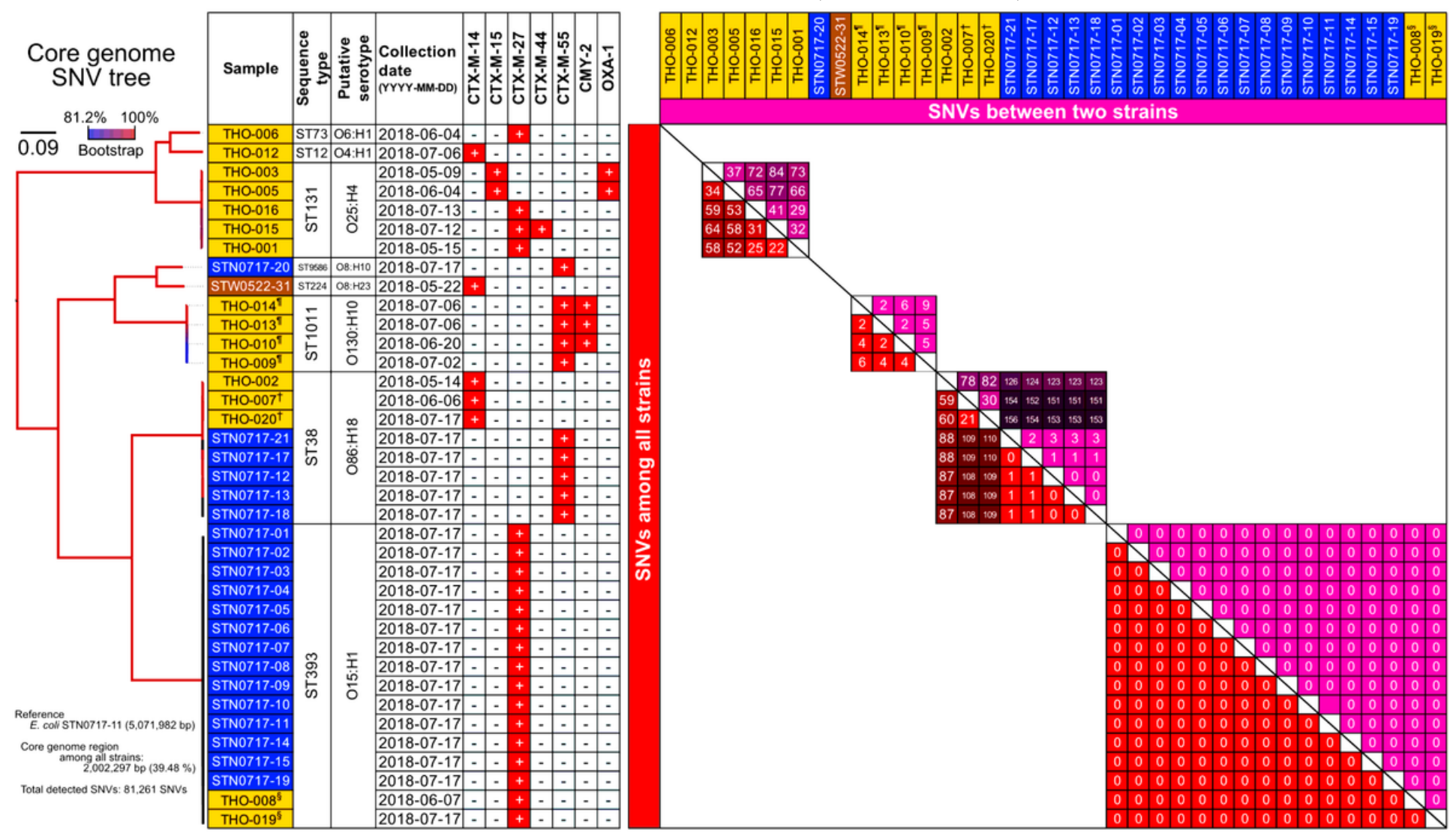

\section{Figure 6}

Core genome phylogeny using single-nucleotide variations (SNVs) of ESBL-producing E. coli isolates. Core genome phylogeny was constructed using ESBL-producing E. coli isolates; 20 clinical isolates (THOnumber, orange highlighted), one sewage isolate from STW0522 (brown highlighted), and 20 sewage isolates from STN0717 (blue highlighted). Complete genome sequence of STN0717-11 was used as a genome reference and $39.48 \%$ of the genome sequence was used as core-genome regions among all tested strains. Few clinical isolates were obtained from same patient (§, patient No.8; 9 , patient No.9; †, patient No.7 in supplement Data Set S1). Heatmap of pairwise differences of core genome SNVs are shown using a color gradient with pink and red. The lower half part indicates core genome SNVs among all strains, and the upper half part shows core genome SNVs between indicated two strains. THO-008 and -019 from Patient No. 8 showed no SNVs with sewage isolates (14 isolates; STN0717-1 to $-11,14$, 15, and 19). There were no identical clones between different patients.

\section{Supplementary Files}


This is a list of supplementary files associated with this preprint. Click to download.

- DataSetS1Metagenome.xlsx

- DataSetS2Isolates.xIsx 